Running head: Employment discrimination against immigrants

\title{
The Skill Paradox: Explaining and Reducing Employment Discrimination against skilled Immigrants
}

\author{
Joerg Dietz $^{* a}$, Chetan Joshi ${ }^{\mathrm{b}}$, Victoria M. Esses ${ }^{\mathrm{c}}$, Leah K. Hamilton ${ }^{\mathrm{d}}$, and \\ Fabrice Gabarrot ${ }^{\mathrm{e}}$ \\ ${ }^{a}$ Faculty of Business and Economics (HEC Lausanne), University of \\ Lausanne, Lausanne, Switzerland \\ ${ }^{b}$ Indian Institute of Management Calcutta, Kolkata, India \\ ${ }^{c}$ Department of Psychology, University of Western Ontario, London, Canada \\ ${ }^{d}$ Bissett School of Business, Mount Royal University, Calgary, Canada \\ ${ }^{e}$ University of Burgundy, Dijon, France
}

Version: November, 2014

Citation:

Dietz, J., Joshi, C., Esses, V. M., Hamilton, L. K., \& Gabarrot, F. (in press). The skill paradox: Explaining and reducing employment discrimination against skilled immigrants. International Journal of Human Resource Management.

Funding:

We are grateful for partial funding of this research by the Social Sciences and Humanities Research Council of Canada (Grant \# 864-2007-0088).

\footnotetext{
* Corresponding author. Email: jorg.dietz@unil.ch
} 


\title{
The Skill Paradox: Explaining and Reducing Employment Discrimination
} against skilled Immigrants

\begin{abstract}
Using a social identity theory approach, we theorized that recruiters might be particularly biased against skilled immigrant applicants. We refer to this phenomenon as a skill paradox, according to which immigrants are more likely to be targets of employment discrimination the more skilled they are. Furthermore, building on the common ingroup identity model, we proposed that this paradox can be resolved through human resource management (HRM) strategies that promote inclusive hiring practices (e.g., by emphasizing fit with a diverse clientele). The results from a laboratory experiment were consistent with our predictions: Local recruiters preferred skilled local applicants over skilled immigrant applicants, but only when these applicants were qualified for a specific job. This bias against qualified and skilled immigrant applicants was attenuated when fit with a diverse clientele was emphasized, but not when fit with a homogeneous clientele was emphasized or when the hiring strategy was not explained. We discuss the implications of our findings for research on employment discrimination against skilled immigrants, including the role of inclusiveness for reducing discriminatory biases.
\end{abstract}

Keywords: human resource management, HRM strategy, employment discrimination, immigrants, social identity theory, diversity, inclusion, person-organization fit 


\section{The Skill Paradox: Explaining and Reducing Employment Discrimination}

\section{against skilled Immigrants}

Skilled immigrants are increasingly becoming an important part of Western labor forces, leading many organizations to devise strategic human resource management (HRM) practices targeting these employees (e.g., Al Ariss and Syed 2011; Zikic, Bonache and Cerdin 2010). Nonetheless, immigrants obtain sub-par outcomes in the labor market (e.g., Galarneau and Morissette 2004; Hakak and Al Ariss 2013), as their skills are systematically devalued. In Canada, for example, the financial value of foreign work experience is about $30 \%$ of that of Canadian work experience, and foreign education is valued at about $70 \%$ of Canadian education (Alboim, Finnie and Meng 2005).

A striking observation is that the more immigrants are skilled and qualified, the less likely they are to find employment relative to their local counterparts. For members of Canada's labor force who do not hold a degree, certificate, or diploma, employment rates are $61.3 \%$ for locals and $61.9 \%$ for immigrants. For those with university degrees, however, the employment rates are $90.9 \%$ for locals and $79.8 \%$ for immigrants, a gap of $11.1 \%$. Whereas in absolute terms the employability of immigrants increases as they possess more advanced skills, it decreases in relative terms to comparable locals. We call this phenomenon the skill paradox. Companies consistently raise consistently concerns about skill shortages (Canadian Manufactures and Exporters 2013), and, hence, the most skilled immigrants ought to be particularly likely to be employed, but the contrary is the case.

The purpose of our research was to investigate this skill paradox. In particular, we sought to understand whether social identity theory (SIT, Tajfel and Turner 1986) could explain such discrimination against skilled immigrants and also serve as a theoretical basis for an intervention against it. In the remainder of this article, after speaking to the motivation behind our study, we review the literature on skill-related employment discrimination against 
immigrants. Then, we use SIT to explain the skill paradox and for designing an intervention to curb discrimination. Next, we present the methods and results of a laboratory experiment conducted with a Canadian sample before concluding with a discussion of our findings.

The motivation for our research was threefold. First, our study has the potential to contribute to the academic literatures on discrimination against immigrants and on SIT. It is not only the first study to develop the notion of the skill paradox, but, unlike most other related studies, also includes a test of an intervention against discrimination. Furthermore, our research might advance knowledge on when an SIT-based bias against outgroup members occurs. Second, we heed calls for research on immigrant employees, the new "invisible men and women" in workforce diversity research (e.g., Bell, Kwesiga and Berry 2010; Dietz 2010). Third, Canada's economy loses over $\$ 11$ billion annually because immigrants' skills are underutilized and up to $\$ 12.6$ billion because they are underpaid (Reitz, Curtis and Elrick 2014). These outcomes are detrimental to immigrants and employers alike (e.g., Bhagat and London 1999; Esses, Dietz and Bhardwaj 2006). Explaining and reducing the underutilization of immigrants' skills, thus, is an economic and social imperative. It is also an ethical imperative as employment discrimination violates the fundamental right of fair treatment (Petersen and Dietz 2008).

\section{Skill-related employment discrimination against immigrants}

Employment discrimination refers to unfair differential treatment of current or prospective employees solely based on their social or demographic group membership (for a review of employment discrimination against immigrants, see Binggeli, Dietz, and Krings, 2013). Skill-related discrimination against immigrants, the focus of our study, has been addressed by scholars from several disciplines, such as human resource management (e.g., Hakak and Al Ariss 2013; Salaff, Greve and Ping 2002), psychology (e.g., Esses, Dietz and Bhardwaj 2004, 2006), and sociology (e.g., Reitz 2007). This type of discrimination has two 
basic facets: Either immigrants' skills, such as their academic and professional degrees as well as their work experience, are unfairly devalued (i.e., skill discounting and the devaluation-based skill paradox) or their skills are valued but viewed as a threat to locals (i.e., the threat-based skill paradox).

\section{Skill discounting and the devaluation-based skill paradox}

Most of the research on skill-related discrimination has examined "skill discounting" (e.g., Li, Gervais and Duval 2006), which can be defined as the devaluation of immigrants' foreign academic education, foreign professional training, and foreign work experience. Skill discounting means that immigrants' skills are evaluated worse than those of locals, even if they are factually of the same quality. It is both an institutional problem (e.g., Salaff et al. 2002) and an individual-level phenomenon in the form of prejudicial biases against immigrant applicants (e.g., Esses et al. 2006).

Salaff et al. (2002), in a study of Chinese migrants to Canada, described numerous cases in which local institutions (e.g., professional boards) did not recognize foreign degrees. For example, a Chinese medical doctor, despite advanced training - including stays in the U.S. - never regained permission to exercise her profession in Canada. Canadian institutions apparently acted as gate-keepers, and often employers insisted on Canadian work experience, resulting in underemployment or unemployment of migrants (see also Fang, Samnani, Novicevic and Bing 2013). Complementing the research by Salaff et al., Esses et al. (2006) studied the discriminatory behavior of personnel decision makers. These personnel decision makers, particularly those who harbored latent prejudices, exhibited a pattern of subtle discrimination: They devalued the foreign skills of an immigrant from a non-Western country, but not those of an immigrant from a Western country.

Skill discounting becomes more costly to immigrant employees as they have more advanced education. It is one explanation for the skill paradox that employment rates for 
immigrants more and more decrease relative to those of comparable locals, as skill levels increase. This devaluation-based skill paradox can be considered as a labor-market wide phenomenon. The more advanced immigrants' foreign skills are, the more difficult their recognition by local institutions turns out to be; if skills are not recognized, chances of finding employment decrease.

\section{Threat-based skill paradox}

In our study, we seek to uncover another facet of skill-related discrimination, namely the threat-based skill paradox. It describes how skilled immigrants are less likely to be employed, even if (or stated better because) their skills are considered as equivalent to those of locals. In this case, immigrants are not excluded due to skill discounting. Instead their degrees are as valued as are those of equally skilled local applicants, but if these skills qualify immigrants for a specific job, immigrants become a threat to local job applicants (note that we use the term skills to refer to skills in general whereas the term qualifications refers to the relevance of skills for a specific job). This threat, in turn, triggers anti-immigrant biases.

Like the devaluation-based skill paradox, the threat-based skill paradox affects highly skilled immigrants more strongly relative to less skilled immigrants because the more advanced immigrants' skills are the more of a threat to locals they pose. The two forms of skill paradoxes differ in that the threat-based skill paradox requires a specific competitive situation between immigrants and locals, whereas the devaluation-based skill paradox refers to the generic devaluation of skills whether immigrants compete with locals or not. They also differ in the process by which they produce discrimination (devaluation of skills versus valued skills as a threat), but they produce the same outcome (i.e. non-employment) for skilled immigrants. 


\section{A social identity theory approach to explaining the threat-based skill paradox}

In this section, we use social identity theory (SIT) to explain why local recruiters might evaluate skilled immigrant applicants less favorably than skilled local applicants but only if these applicants are qualified for a specific job. We then turn to the influence of HRM strategies on these paradoxical evaluations, examining whether an HRM strategy that emphasizes fit with a diverse clientele can reduce anti-immigrant biases.

\section{Social identity theory (SIT) and the threat-based skill paradox as ingroup bias}

SIT is well suited to explain employment discrimination against skilled immigrants (e.g., Coates and Carr 2005), including the threat-based skill paradox. Central to SIT is the notion of the social self (or group self, Ellemers 2012), according to which individuals define in part who they are through their membership in social groups (for recent reviews of SIT, see Abrams and Hogg 2010, and Ellemers and Haslam 2011). For example, recruiters might define their identity in part by whether they are immigrants or local citizens. Which ingroup/outgroup categorizations are salient depends on characteristics of both the situation and the person (Ashforth and Johnson 2001). In a personnel decision context, immigrant status may be a criterion that demarcates one group of job applicants from another group. For local recruiters, immigrant status then becomes a salient group category with locals as the ingroup and immigrants as the outgroup.

Moreover, SIT posits that individuals are motivated to acquire and maintain a positive self-concept, including a positive social self. They, hence, tend to promote the image of their social groups, which can result in preferential treatment of ingroup members over outgroup members (Dovidio and Gaertner 2010). Under certain conditions, however, ingroup biases do not manifest. SIT itself suggests such a condition: Ingroup bias should not occur when it does not contribute to a positive image of the ingroup. This image-enhancing function of ingroup bias is particularly relevant in situations when groups compete for scarce resources, such as 
jobs (Abrams and Hogg 2010). Thus, the preferential treatment of ingroup members depends on their ability to represent the ingroup in a positive light. Those ingroup members who can do so are preferred over comparable outgroup members. In contrast, ingroup members who threaten to undermine the positive ingroup image (for example, because they are less qualified) are not favored (Lewis and Sherman 2003).

In our research, we investigate this conditional ingroup bias as an explanation for employment discrimination against skilled immigrants. Local recruiters encounter skilled applicants who differ in their immigrant status and in their qualifications for a specific job. According to the logic of the conditional ingroup bias, on one hand, we expect that local recruiters evaluate skilled immigrant applicants who are qualified for a specific job less favorably than comparable local applicants. The latter should do a good job and, hence, represent the local ingroup well. On the other hand, local recruiters should not inflate the evaluations of less qualified local applicants relative to those of less qualified immigrant applicants. If less qualified local applicants were evaluated too favorably and therefore selected, they might fail on the job which constitutes a threat to the positive image of the ingroup. On the basis of these arguments, we hypothesized an interactive effect between the immigrant status of applicants and their qualifications on their evaluations by local recruiters: Hypothesis 1: Local recruiters evaluate immigrant applicants as less suited for a job relative to local applicants, if immigrant and local applicants are qualified, but not if these applicants are less qualified.

Hypothesis 1 postulates a manifestation of the threat-based skill paradox. Below we draw on the common ingroup identity model (Gaertner and Dovidio 2000) to explain how an HRM strategy that promotes inclusive hiring practices can be an intervention against this paradox. 


\section{The common ingroup identity model as a basis for inclusive HRM strategies}

If social identity motives underlie biases against qualified immigrant applicants, organizations might affect these biases through managing these motives, for example, by using the common ingroup identity model (Gaertner and Dovidio 2000; Gaertner et al. 2000). This model suggests that ingroup biases can be reduced through the redefinition of groups at a more inclusive level of identity. "If members of different groups are induced to conceive of themselves within a single group rather than completely separate groups, attitudes towards former outgroup members will become more positive through the cognitive and motivational processes involving pro-ingroup bias" (Gaertner and Dovidio 2000, p. 46). An emphasis on a single, inclusive group leads to the transformation of original $u s$ versus them categorizations into one we identity (Gaertner and Dovidio 2008).

Gaertner and Dovidio (2008, p. 116) argued that "supportive norms by authorities" might be sufficient for modifying cognitive representations of the ingroup and developing a common ingroup identity. In support of this argument, Hertel and Kerr (2001) found that inclusive norms of equality compared to exclusive norms for ingroup loyalty led to less ingroup favoritism. Despite its promise for reducing favoritism in personnel decisions, HRM scholars have largely ignored the common ingroup identity model. Petersen and Dietz (2005) did not explicitly draw on this model, but they examined the effect of an exclusive identity in form of an HRM strategy that emphasized fit with a homogenous staff on hiring decisions involving German and foreign applicants. When demographic homogeneity was emphasized, participants selected fewer foreign applicants despite equal qualifications.

Whereas Petersen and Dietz (2005) examined the effects of an exclusive HRM strategy, our focus is on the effects of an inclusive hiring strategy that emphasized fit with a diverse clientele (see also Brief, Dietz, Cohen, Pugh and Vaslow 2000 and Powell 1999 for discussions of fit between employees and customers). We expected that a manipulation of fit 
with the clientele would affect whether only qualified local applicants or both qualified local and qualified immigrant applicants benefitted from ingroup bias. The fit-with-a-diverseclientele HRM strategy suggested a larger ingroup, consisting of both Canadian locals and immigrant residents, whereas the fit-with-a-homogeneous-clientele HRM strategy implied that the ingroup consisted of Canadian locals only. We hypothesize:

Hypothesis 2. Local recruiters evaluate qualified immigrant applicants as less suited for a job than equally qualified local applicants, when fit with a homogeneous clientele is emphasized or when no information about the fit with the clientele is given, but not when fit with a diverse clientele is emphasized.

Below, we report the methods and results of a study to test our hypotheses.

\section{Methods}

\section{Overview}

To test our hypotheses, we chose an experimental laboratory setting because the threat-based skill paradox, to our knowledge, has not yet been studied and because we sought to establish the internal validity of the hypothesized effects. Participants were recruited for a study ostensibly on managerial decision making. They made numerous decisions in an inbasket exercise, assuming the role of head of human resources of a Canadian restaurant chain. In-basket exercises are commonly used in assessment centers for gauging managerial potential (e.g., Thornton 1992).

Embedded in the exercise was a personnel decision task which included the manipulations of the independent variables. The experimental design was a mixed $2 \times 2 \times 3$ factorial design: Applicants' immigrant status (local or immigrant) and qualification level (qualified or less qualified) were within-participants factors, and fit-with-the-clientele (fitwith-a-diverse-clientele, fit-with-a-homogeneous-clientele, or fit not explained [control condition]) was a between-participants factor. The dependent variable was the evaluation of 
applicant suitability for a job. For the personnel decision task, each participant was randomly assigned to one fit-with-the-clientele condition and evaluated nine applicants (two qualified local applicants, three less qualified local applicants, two qualified immigrant applicants, and two less qualified immigrant applicants).

\section{Participants}

One hundred sixty five ( $78.8 \%$ female) undergraduate psychology students at a large Canadian university voluntarily participated in the study in exchange for course credit. The average age was $20.77(S D=5.24)$ years. All participants were Canadian citizens. The majority of participants were White $(81.8 \%)$ and born in Canada $(84.8 \%)$.

\section{Manipulations and Measures}

\section{Manipulation of immigrant status}

One of the managerial decisions in the in-basket exercise involved rating nine applicants for a restaurant manager position. For each applicant, participants reviewed a summary sheet, which indicated immigrant status in two ways: (1) The five local applicants had obtained their education and work experience in Canada, whereas the four immigrant applicants had obtained their education and work experience in other Western countries; and (2) immigrant status was described as "landed immigrant" (a Canadian term for an officially admitted immigrant) for immigrant applicants or as "Canadian citizen" for local applicants. Mentioning the immigrant status is common in resumes to ensure that applicants have a work permit. To rule out that discrimination would occur on the basis of language proficiency, gender, ethnic or non-Western background, we kept these factors constant: immigrant applicants were white males from Western countries who spoke English fluently. Manipulation of qualification level

Four applicants (two locals and two immigrants), who were qualified for the position, had both job-related education and work experience. The remaining five applicants (3 locals 
and 2 immigrants) had either job-related education or job-related experience, but not both; hence, they were less qualified for the position. As reported in the next paragraph, we pretested the applicant profiles for the perceived level of qualification.

The pretest involved a separate sample (i.e., participants in the pretest did not partake in the main study) of 42 undergraduate students (all Canadian citizens). They rated the overall suitability for the position of the nine applicants used in the main study based on profiles that excluded immigrant status information. Participants were informed that candidates should have experience in the restaurant industry and a job-relevant university degree. As expected, overall suitability for the group of the four better qualified applicants was rated higher than that for the group of the five lesser qualified applicants, $M=5.63(S D=$ $.61)$ versus $3.52(S D=.93) ; t(41)=13.63, p<.001$. The results of the pretest also indicated that, among better qualified applicants, those with Canadian qualifications and those with non-Canadian qualifications were not evaluated differently, $M=5.61(S D=.82)$ versus 5.65 $(S D=.72), t(41)=-.33, n s$. The same pattern was found among less qualified applicants, $M=$ $3.45(S D=.92)$ for those with Canadian qualifications, and $M=3.62(S D=1.09)$ for those with non-Canadian qualifications, $t(41)=-1.48, n s$. The pretest showed that non-Canadian university degrees per se (when the immigrant status of their holders was not indicated) were not discounted.

\section{Manipulation of Fit with the Clientele}

Participants were randomly assigned to one of three between-participants conditions. In all three conditions, participants received a memorandum from the President of the restaurant chain instructing them to keep in mind two criteria - experience in managing restaurants, and a university degree in a job-related field (e.g., business) - while evaluating applicants who had been prescreened by the HR department. The President stated:

(1) The candidate has to have experience in managing restaurants. I do not want someone whom we have to train from the ground up, even if he or she may be a 
very promising candidate.

(2) The job market is saturated with qualified applicants, which allows us to elevate the educational profile of the restaurant manager position. Hence, the candidate has to have a university degree in business or commerce, food and hospitality management, or service management.

In the fit-with-a-diverse-clientele condition, an additional instruction stated that:

(3) The vast majority of our customers in Windsor are middle-class families with household incomes around $\$ 70,000$, who come from a rich diversity of ethnic backgrounds. The new restaurant manager will do better, if he/she matches this demographic profile. Mary Copeland, the VP Marketing, also endorses the notion of matching on employee and customer demographics because it makes it easier to run local advertising and promotion campaigns.

In the fit-with-a-homogeneous-clientele condition, the additional instruction stated that:

(3) The vast majority of our customers in Windsor are average Canadian, local, middle-class families with household incomes around $\$ 70,000$. The new restaurant manager will do better if he/she matches this demographic profile. Mary Copeland, the VP Marketing, also endorses the notion of matching on employee and customer demographics because it makes it easier to run local advertising and promotion campaigns.

In the control condition, an additional instruction about fit with the clientele was not provided. Our choice of operationalization (i.e., the reference to the customer profile) was in part driven by Almeida, Fernando and Sheridan's (2012) finding that the ethnic diversity of clients was a factor that affected employers' willingness to consider immigrant applicants.

\section{Dependent variable}

Participants rated each applicant's overall suitability for the job on a seven-point scale with higher scores indicating better suitability. We calculated an average of these ratings for the two qualified locals, two qualified immigrants, three less qualified locals and two less qualified immigrants. Coefficient alphas (Cronbach 1951) for the overall suitability measures were $.69, .76, .84$ and .75 respectively, indicating that participants evaluated applicants from the same experimental cell (i.e., qualified locals, qualified immigrants, less qualified locals, and less qualified immigrants) consistently. 


\section{Manipulation checks}

After the in-basket exercise participants completed manipulation check items, a demographic questionnaire, and were debriefed. The manipulation check items asked whether the job required work experience in restaurants, a university degree in a restaurant-related discipline, and whether the applicants should match the average demographic profile of customers who were (a) average Canadian, local, middle class families or (b) were middleclass families who came from a rich diversity of ethnic backgrounds.

\section{Results}

\section{Manipulation checks}

The vast majority of participants $(87.3 \%)$ correctly reported that applicants should have work experience in restaurants, $\chi^{2}(1, N=165)=91.69, p<0.001$. Moreover, $87.9 \%$ correctly reported that applicants should have a university degree in a restaurant-related discipline, $\chi^{2}(1, N=165)=94.69, p<0.001$. Overall, $77.6 \%$ of the participants correctly reported that applicants should have both work experience in restaurants and a university degree in a restaurant-related discipline, $\chi^{2}(1, N=165)=50.19, p<0.001$. Concerning the manipulation of fit-with-the-clientele (diverse/homogeneous/control), $82.2 \%$ of participants correctly reported the expected demographic profile of customers, $\chi^{2}(1, N=163)=67.64, p$ $<0.001$.

Below we report the results on the full sample of 165 participants. Analyses on only those 128 participants who had responded correctly to the manipulation checks for both qualification criteria produced an identical of results with one exception: The interaction terms for testing our hypotheses were only marginally significant $(p<.10)$ due to reduced power (see Aguinis, 1995, for discussing difficulties in detecting significant interactions). 


\section{Main Analyses}

Table 1 shows the cell means for the dependent variable applicant overall suitability. Tables 2 and 3 show the results of within-between analyses of variance. We controlled for participant gender, age, ethnicity, and country of birth. The pattern of results was identical when we did not include the control variables. To provide full information, below we report the results with the control variables.

\section{Please insert Tables 1 and 2 about here.}

\section{Test of Hypothesis 1}

Table 2 shows the test of Hypothesis 1 that local participants evaluate the job suitability of immigrant applicants less favorably than that of local applicants, if applicants are qualified but not if applicants are less qualified. We found significant main effects for both immigrant status and qualification level. Overall, participants evaluated local applicants more favorably than immigrant applicants $(M=5.09, S D=.72$ versus $M=4.93, S D=.82)$. Participants also evaluated qualified applicants more favorably than less qualified applicants $(M=5.84, S D=.71$ versus $M=4.18, S D=.91)$. These main effects, however, were qualified by a significant interaction effect that was the test of Hypothesis 1 . Consistent with this hypothesis, participants evaluated qualified local applicants more favorably than qualified immigrant applicants $(M=5.99, S D=.77$ versus $M=5.69, S D=.84, t(158)=5.22, p<$ $.001)$. However, differences in the evaluations of less qualified local and less qualified immigrants applicants were not observed $(M=4.18, S D=.90$ versus $M=4.18, S D=1.04$, $t(158)=.02, n s)$.

Test of Hypothesis 2

According to Hypothesis 2, the positive bias in favor of local applicants is alleviated when fit with a diverse clientele is emphasized, but not when fit with a homogeneous clientele is emphasized or no information about fit with the clientele is given. Table 2 shows 
a significant interaction effect between immigrant status and fit with the clientele, indicating that the differences in evaluations of immigrant applicants and local applicants varied by which type of fit was emphasized. Participants evaluated local applicants more favorably than immigrant applicants in both the control condition $(M=5.12, S D=.76$ versus $M=4.97, S D=$ .70 , respectively, $t(158)=2.06, p<.05)$ and the fit-with-a-homogenous-clientele condition $(M=5.09, S D=.67$ versus $M=4.80, S D=.85$, respectively, $t(158)=4.09, p<.001)$. Such a difference, however, was not found in the fit-with-a-diverse-clientele condition $(M=5.06, S D$ $=.79$ versus $M=5.05, S D=.84$, respectively, $t(158)=0.11, n s)$.

In a further analysis on qualified applicants only (see Table 3), we found a significant main effect of immigrant status, such that qualified local applicants were evaluated more favorably than were qualified immigrant applicants. This main effect was qualified by an interaction: In support of Hypothesis 2, the effect of immigrant status was moderated by fit with the clientele. The pattern of the interaction was such that in the fit-with-a-diverseclientele condition, the overall suitability of qualified local applicants did not differ significantly from that of qualified immigrant applicants $(M=5.88, S D=.92$ versus $M=$ $5.75, S D=.88, t(158)=1.07, n s)$. In contrast, in the other two conditions, qualified local applicants were rated as more suitable than were qualified immigrant applicants $(M=6.08$, $S D=.68$ versus $M=5.56, S D=.83, t(158)=5.34, p<.001$, in the fit-with-a-homogenousclientele condition, and $M=6.03, S D=.69$ versus $M=5.76, S D=.80, t(158)=2.66, p<.01$, in the control condition). Finally, when we ran the same analysis of variance for the less qualified applicants, we did not find a single significant main effect or interaction effect.

\section{Please insert Table 3 about here.}

\section{Discussion}

Although skilled immigrants from Western countries are often considered to have a plethora of opportunities in their host countries, our research shows that they also face 
discrimination, albeit in subtle forms. More specifically, our study demonstrated a threatbased skill paradox, such that skilled immigrant applicants were targets of employment discrimination, when they were qualified for a job but not when they were less qualified (Hypothesis 1). We also found that an HRM strategy that promoted inclusive hiring practices (by emphasizing fit with a diverse clientele) could suppress this bias (Hypothesis 2). We discuss the implications of these findings below, starting with their contributions to the literature, followed by the practical implications of our research as well as its limitations.

\section{Contribution to the literature on employment discrimination against immigrants}

Our study addresses two gaps in the literature. First, we introduce and provide initial evidence for a skill paradox, according to which in particular skilled and qualified immigrants are likely to face employment discrimination. Second, our study provides a test of an intervention that curtails discrimination against skilled immigrants.

Employment discrimination against immigrants: The skill paradox

In reaction to calls for research on employment discrimination against immigrants (e.g., Bell, Kwesiga and Berry 2010; Dietz 2010), we advanced the notion of a skill paradox that puts skilled immigrants at a particular disadvantage in the labor market. The unemployment of highly skilled immigrants might not just result from disproportionately negative effects of skill discounting (the devaluation-based skill paradox) but also, as our research implies, from locals' perceptions of immigrants' skills as a threat. The result is a "catch 22" situation for immigrants: they experience discrimination either because their skills are discounted or because their skills are valued but considered a threat to the careers of locals.

Social identity theory explains the threat-based skill paradox, hence, addressing Dietz's (2010) question of whether immigrant status is a relevant marker for ingroup/outgroup categorizations. Stated bluntly, in our study, qualified immigrants were 
targets of discrimination because they were immigrants, not because they had seemingly subpar skills, belonged to different ethnic or gender groups, or did not speak the local language. Moreover, by examining the discriminatory behavior of recruiters, our research complements investigations into the outcomes for immigrants as targets of discrimination (e.g., Fang et al. 2013; Hakak et al. 2010). Zooming in on recruiters' behaviors provides a close look at a key source of discrimination, namely their biases. If we had studied the direct effect of inclusive hiring strategies on outcomes for immigrants, it would not have been clear whether recruiters' reactions to such strategies or those of immigrants caused these outcomes.

Whereas we focused on the threat-based skill paradox, future research should also target the devaluation-based skill paradox. Despite research on skill discounting (e.g., Reitz 2007, Esses et al. 2006), relatively little is known about why the gap between the value of foreign and local skills widens as skill levels increase. A possible explanation is status protection: for example, advanced academic degrees are associated with high status both for the degree holders and the professions, in which these degrees are required. Discounting, for example, doctoral degrees obtained by immigrants assures that this high status is not tainted by the relatively lower societal status of immigrants. Another possible explanation is that the competition for high-skill jobs is fiercer than that for low-skill jobs, and then skill discounting eliminates immigrants as competitors.

\section{HRM strategies that emphasize fit with the clientele}

By testing HRM strategies that emphasize fit with the clientele as an intervention against discrimination, our study speaks to Roberson, Galvin and Charles' (2007) concern that in research on biases in personnel decisions "the biggest gap between theory and research concerns organizational moderator variables" (p. 637). Studying HRM strategy as such a moderator is crucial as it shows when recruiters' discriminatory biases can be reduced and when not. 
The theoretical basis for our intervention was the common ingroup identity model, which is about creating more inclusive ingroups and, thereby, enabling a larger group to benefit from ingroup biases. Hence, ingroup bias is not suppressed but strategically used to reduce discrimination. Numerous future research questions arise: first, our manipulation of HRM strategies via their emphasis on fit with the clientele might be replaced by manipulations that more directly vary levels of inclusiveness. Second, there is a need to replicate our research in the field. One possibility is to classify organizations as more or less inclusive on the basis of publicly available material and to then conduct an audit study with recruiters of these companies. Alternatively, a more qualitative approach could be used in an interview study of recruiters and ideally also job applicants (e.g., Al Ariss and Özbilgin 2010). Third, the common ingroup identity model suggests several other mechanisms in addition to inclusive norms by which such an identity could be modeled. For example, to test the power of wording, a study in which the use of "us versus them" or "we" language is manipulated offers a starting point.

More broadly speaking, we have shown the effect of an HRM strategy that emphasizes fit with a diverse clientele on biases against immigrant applicants, suggesting that HRM models that foster inclusiveness (e.g., Mor Barak 2011) can have a positive effect on hiring immigrant employees. Our research, however, also shows that HRM strategies that are based on person-organization fit (i.e., person-customer fit in our research) are a double-edged sword, which can result in exclusion of immigrants, if the clientele is homogeneous. Hence, we provide empirical input into the critical debate about the argument that HRM policies of matching staff and clientele on demographic characteristics contribute to organizational effectiveness, which is central to the business case for diversity (e.g., Brief et al. 2000; Powell 1999). 


\section{Contribution to the literature on social identity theory}

\section{Conditional ingroup bias}

In our study, local recruiters favored only qualified members of the local ingroup, but not less qualified ones who threatened the positive image of the ingroup. This conditional ingroup bias (i.e., ingroup favoritism was extended to only those ingroup members who represented the ingroup well) demonstrates the usefulness of SIT for understanding employment discrimination, but also suggests a new nuance of SIT, as explained below.

We consider the conditional ingroup bias as a variant of the black-sheep effect (Marques, Abrams and Serodio 2001; Marques, Yzerbyt and Leyens 1988), according to which poor performance is evaluated more negatively when it is attributed to an ingroup member as compared to an outgroup member. Both the black-sheep effect and the conditional ingroup bias seek to protect the image of the ingroup. To do so, however, the black-sheep effect uses derogation of low-performing ingroup members, whereas the conditional ingroup bias relies on overly favorable treatment of high-performing ingroup members while lowperforming group members are treated fairly.

Whether the black-sheep effect or the conditional ingroup bias occurs depends on the extent to which bad representatives threaten the ingroup image. To apply the metaphor of the black-sheep effect, fully unqualified ingroup members are black sheep that are derogated. The partially unqualified ingroup members in our study, however, could be seen as grey sheep that are not treated as negatively as black sheep, but that also do not receive the same positive treatment as do white sheep (fully qualified ingroup members). To conclude, the conditional ingroup bias (or what might be called a grey-sheep effect) is an example of the use of SIT, in which intragroup differentiation (i.e., the need to distinguish oneself positively from bad representatives of the ingroup) and intergroup differentiation (i.e., the need to 
distinguish one's group positively from other groups) operate jointly to protect one's selfesteem while not undermining those members of the ingroup who represent it poorly. Robustness in comparison to potential alternative theoretical explanations

We considered alternative explanations of the current findings, namely the lack-of-fit model (Heilman, 1983), theories of intergroup threat (e.g., Esses, Medianu and Lawson 2013), and theories of obedience to organizational authorities (e.g., Hamilton and Sanders 1999), but found the SIT approach to be a more suitable explanation for the threat-based skill paradox. First, whereas the lack-of fit model explains employment discrimination in stereotyped jobs, our reasoning also applies to non-stereotyped jobs. Moreover, unlike the lack-of-fit model, our argument is not that local recruiters assume that immigrants as outgroup members will not succeed in their jobs, but that, in order to boost the image of their local ingroup, local recruiters prefer qualified local applicants. Second, threat theories are less well suited to explain why only qualified but not less qualified immigrants would pose a threat. Instead, threat theories would imply that all immigrants, whether qualified or not, endanger the dominant position of the ingroup. Third, the effects of fit with the clientele were likely not compliance phenomena in light of the pattern of main effects and interactive effects. For example, compliance-based arguments would suggest that discrimination against immigrants should have been more pronounced in the fit-with-a-homogenous-clientele condition than in the control condition, but this was not the case.

\section{Contribution to practice}

In discussing practical implications, we note that our laboratory experiment only showed that effects can occur, not that they do occur in the field. Hence, our research is more of a reflection point for HR managers than a how-to-do guide for reducing employment discrimination. One reflection point is that an HRM strategy that emphasizes fit with a diverse clientele can level the playing field for local and immigrant applicants. A level- 
playing field is good news to both immigrant employees and local employees, as the latter do not have to fear so-called reverse discrimination (i.e., that they would become targets of discrimination). Thus, emphasizing fit with a diverse clientele can create a win-win situation. In contrast, an exclusive hiring strategy or ignoring fit with the clientele can result in a winlose situation with qualified and skilled immigrant applicants being on the losing end.

Moreover, the finding of the threat-based skill paradox conveys the message to recruiters that biases can creep into personnel decisions in counterintuitive ways and result in poor decisions that have detrimental consequences for organizations and immigrant applicants. Who would expect (1) that well-qualified immigrants applicants should experience more discrimination in hiring situations than less qualified immigrant applicants and (2) that appropriate skills and qualifications could be reasons for not being hired?

\section{Limitations}

We decided to conduct our study in a laboratory setting to maximize internal validity. The trade-off is reduced external validity by, for example, having participants assess "paper" job candidates (e.g., Gorman, Clover and Doherty 1978). Furthermore, the vast majority of our participants were female students, who had to evaluate exclusively male applicants. For managing participant comfort and enhancing ecological validity, it would have been preferable to have both female and male applicants. Such a set-up would, however, have enhanced the required sample size and possibly introduced a complexity that could have undermined internal validity. Furthermore, the coefficient alphas for evaluations of equally qualified applicants of the same citizenship status (immigrant or local) were relatively low as a function of having only two or three applicants per group. A larger number of applicants could have resolved this issue.

In addition, our data were collected in a Canadian context. Canada, unlike, for example, Western European nations, is an immigrant nation, and its policies have 
traditionally emphasized cultural pluralism (the so-called mosaic, with which Canadian children are already confronted in kindergarten). It remains to be seen whether our finding of subtle discrimination against immigrants can be replicated in countries that are relatively less open towards immigrants and/or pursue more assimilatory policies. In sum, for numerous reasons, the generalizability of our findings to "real world" settings remains an open empirical question that awaits further testing in the field.

Furthermore, we manipulated inclusion by stating that customers came from a rich diversity of ethnic backgrounds and that new employees should match the customer profile. Although we consider this operationalization as implying an HRM strategy that promotes inclusive hiring practices, it might be argued that it captures only fit with customers. A more explicit and direct operationalization of inclusion as an HRM strategy (e.g., by stating that employees from all demographic groups and with diverse backgrounds should be considered and equally treated) would have provided more direct and possibly stronger evidence for the common identity model.

Finally, on the basis of Hypothesis 2, a three-way interaction between qualification level, immigrant status, and fit-with-the-clientele might have been plausible. We did not find such an interaction, which in part is likely due to the very strong effect of qualification level that explained $74 \%$ of the variance in applicants' suitability ratings, thus, not leaving sufficient variance to be explained by higher-order effects. It remains noteworthy, however, that, as Table 1 shows, we found the expected pattern of effects for qualified applicants (i.e., support for Hypothesis 2). Moreover, the absence of significant differences between the evaluations of less qualified local applicants and those of less qualified immigrant applicants across fit-with-the-clientele conditions was consistent with our reasoning. 


\section{Conclusion}

Our study is a tale of two stories. On one hand, it provides evidence of employment discrimination against skilled immigrants, but, on the other hand, it also suggests that organizations, through their HRM strategies, can mitigate such discrimination. It is counterintuitive that skilled immigrants from Western countries should be targets of employment discrimination, as they possess highly sought-after skills. Yet, our study shows that particularly those immigrants who are highly qualified for a job are evaluated less favorably than are their local counterparts. This skill paradox ultimately results in the exclusion of immigrants from labor forces, ironically because these immigrants are so highly skilled and qualified.

Our study, however, also suggests that companies can take effective measures against such discrimination. These measures have less to do with assisting immigrants in their adjustment to the host country (e.g., through cross-cultural training), but rather with the fundamental corporate philosophy for treating employees. If HRM strategies emphasize inclusiveness, for example, by emphasizing fit with a diverse clientele, skilled and qualified immigrant employees are fairly evaluated and, if then hired, can help their companies succeed. Inclusiveness means that companies clearly state and act in a way that employees from different demographic groups, including immigrants, all belong to the ingroup. Thus, an HRM strategy that promotes inclusive hiring practices can contribute to leveling the playing field for immigrant and local employees. 


\section{References}

Abrams, D., and Hogg, M.A. (2010), 'Social Identity and Self-Categorization', in The Sage Handbook of Prejudice, Stereotyping and Discrimination, eds. J.F. Dovidio, M. Hewstone, P. Glick, and V.M. Esses, London: Sage, pp. 179-193.

Aguinis, H. (1995), 'Statistical Power Problems with Moderated Multiple Regression in Management Research', Journal of Management, 21, 1141-1158.

Al Ariss, A., and Özbilgin, M. (2010), 'Understanding Self-Initiated Expatriates: Career Experiences of Lebanese Self-Initiated Expatriates in France', Thunderbird International Business Review, 52, 275-285.

Al Ariss, A., and Syed, J. (2011), 'Capital Mobilization of Skilled Migrants: A Relational Perspective', British Journal of Management, 22, 286-304.

Alboim, N., Finnie, R., and Meng, R. (2005), 'The Discounting of Immigrants' Skills in Canada: Evidence and Policy Recommendations', IRPP Choices, 11, 1-28.

Almeida, S., Fernando, M., and Sheridan, A. (2012), 'Revealing the Screening: Organisational Factors Influencing the Recruitment of Immigrant Professionals', The International Journal of Human Resource Management, 23, 1950-1965.

Ashforth, B.E., and Johnson, S.A. (2001), 'Which Hat to Wear? The Relative Salience of Multiple Identities in Organizational Contexts', in Social Identity Processes in Organizational Contexts, eds. M.A. Hogg, D.J. Terry, Philadelphia: Psychology Press, pp. 31-48.

Barak, M.E.M. (2013), Managing Diversity: Toward a Globally Inclusive Workplace, London: Sage.

Bell, M.P., Kwesiga, E.N., and Berry, D.P. (2010), 'Immigrants: The New "Invisible Men and Women" In Diversity Research', Journal of Managerial Psychology, 25, 177188. 
Bhagat, R.S., and London, M. (1999), 'Getting Started and Getting Ahead: Career Dynamics of Immigrants', Human Resource Management Review, 9, 349-365.

Binggeli, S., Dietz, J., and Krings, F. (2013), 'Immigrants: A Forgotten Minority', Industrial and Organizational Psychology, 6, 107-113.

Brief, A.P., Dietz, J., Cohen, R.R., Pugh, S.D., and Vaslow, J.B. (2000), 'Just Doing Business: Modern Racism and Obedience to Authority as Explanations for Employment Discrimination', Organizational Behavior and Human Decision Processes, 81, 72-97.

Canadian Manufacturers and Exporters (2013), 2012-13 Management Issues Survey, retrieved February 19, 2014, from http://www.cme$\underline{\text { mec.ca/download.php?file=h8q3snma.pdf }}$

Coates, K., and Carr, S.C. (2005), 'Skilled Immigrants and Selection Bias: A Theory-Based Field Study from New Zealand', International Journal of Intercultural Relations, 29, 577-599.

Cronbach, L.J. (1951), 'Coefficient Alpha and the Internal Structure of Tests', Psychometrika, 16, 297-334.

Dietz, J. (2010), 'Introduction to the Special Issue on Employment Discrimination against Immigrants', Journal of Managerial Psychology, 25, 104-112.

Dovidio, J.F., and Gaertner, S.L. (2010), 'Intergroup Bias', in Handbook of Social Psychology (Vol. 2, 5th ed.), eds. S.T. Fiske, D. Gilbert, and G. Lindzey, New York: Wiley, pp. 1084-1121.

Ellemers, N. (2012), ‘The Group Self’, Science, 336, 848-852.

Ellemers, N., and Haslam, S.A. (2011), 'Social Identity Theory', in Handbook of Theories in Social Psychology, eds. A.M. Van Lange, A.W. Kruglanski, and E.T. Higgins, London: Sage, pp. 379-398. 
Esses, V.M., Dietz, J., and Bhardwaj, A. (2004), 'Race, Prejudice, and the Evaluation of Immigrant Skills', International Journal of Psychology, 39(5-6), 9-9.

Esses, V.M., Dietz, J., and Bhardwaj, A. (2006), 'The Role of Prejudice in the Discounting of Immigrant Skills,' in Cultural Psychology of Immigrants, ed. R. Mahalingam, New Jersey: Lawrence Erlbaum, pp. 113-130.

Esses, V.M., Medianu, S., and Lawson, A.S. (2013), 'Uncertainty, Threat, and the Role of the Media in Promoting the Dehumanization of Immigrants and Refugees', Journal of Social Issues, 69, 518-536.

Fang, T., Samnani, A.-K., Novicevic, M.M., and Bing, M.N. (2013), 'Liability-ofForeignness Effects on Job Success of Immigrant Job Seekers', Journal of World Business, 48, 98-109.

Gaertner, S.L., and Dovidio, J.F. (2000), Reducing Intergroup Bias: The Common Ingroup Identity Model, Philadelphia: Psychology Press.

Gaertner, S.L., and Dovidio, J.F. (2008), ‘Addressing Contemporary Racism: The Common Ingroup Identity Model', in Motivational Aspects of Prejudice and Racism, ed. C. Willis-Esqueda, New York: Springer Science, pp. 111-133.

Gaertner, S.L., Dovidio, J.F., Nier, J.A., Banker, B.S., Ward, C.M., Houlette, M., and Loux, S. (2000), 'The Common Ingroup Identity Model for Reducing Intergroup Bias: Progress and Challenges', in Social Identity Processes: Trends in Theory and Research, eds. R. Brown, and D. Capozza, London: Sage, pp. 133-148.

Galarneau, D., and Morissette, R. (2004), 'Immigrants: Settling for Less?', Perspectives on Labour and Income, 5, 5-16.

Gorman, C.D., Clover, W.H., and Doherty, M.E. (1978), 'Can We Learn Anything about Interviewing Real People from "Interviews" of Paper People? Two Studies of the 
External Validity of a Paradigm', Organizational Behavior and Human Performance, $22,165-192$.

Hakak, L.T., and Al Ariss, A. (2013), 'Vulnerable Work and International Migrants: A Relational Human Resource Management Perspective', The International Journal of Human Resource Management, 24, 4116-4131.

Hakak, L.T., Holzinger, I., and Zikic, J. (2010), 'Barriers and Paths to Success: Latin American MBA's Views of Employment in Canada', Journal of Managerial Psychology, 25, 159-176.

Hamilton, V.L., and Sanders, J. (1999), 'The Second Face of Evil: Wrongdoing in and by the Corporation', Personality and Social Psychology Review, 3, 222-233.

Heilman, M. E. (1983), 'Sex Bias in Work Settings: The Lack of Fit Model,' in B. M. Staw, and L. L. Cummings (eds.), Research in Organizational Behavior, Vol. 5. Greenwich, CT: JAI, pp. 269-298.

Hertel, G., and Kerr, N.L. (2001), 'Priming In-Group Favoritism: The Impact of Normative Scripts in the Minimal Group Paradigm', Journal of Experimental Social Psychology, $37,316-324$.

Lewis, A.C., and Sherman, S.J. (2003), 'Hiring You Makes Me Look Bad: Social-Identity Based Reversals of the Ingroup Favoritism Effect', Organizational Behavior and Human Decision Processes, 90, 262-276.

Li, C., Gervais, G., and Duval, A. (2006), The Dynamics of Overqualification: Canada's Underemployed University Graduates, Statistics Canada, Income Statistics Division.

Marques, J., Abrams, D., and Serodio, R.G. (2001), 'Being Better by Being Right: Subjective Group Dynamics and Derogation of In-Group Deviants when Generic Norms are Undermined', Journal of Personality and Social Psychology, 81, 436. 
Marques, J.M., Yzerbyt, V.Y., and Leyens, J.P. (1988), 'The "Black Sheep Effect”: Extremity of Judgments towards Ingroup Members as a Function of Group Identification', European Journal of Social Psychology, 18, 1-16.

Petersen, L.E., and Dietz, J. (2005), 'Prejudice and Enforcement of Workforce Homogeneity as Explanations for Employment Discrimination', Journal of Applied Social Psychology, 35, 144-159.

Petersen, L.E., and Dietz, J. (2008), ‘Employment Discrimination: Authority Figures’ Demographic Preferences and Followers' Affective Organizational Commitment', Journal of Applied Psychology, 93, 1287-1300.

Powell, G.N. (1999), 'The Simultaneous Pursuit of Person-Organization Fit and Diversity', Organizational Dynamics, 28, 50-60.

Reitz, J.G. (2007), 'Immigrant Employment Success in Canada, Part I: Individual and Contextual Causes', Journal of International Migration and Integration/Revue de l'Integration et de la Migration Internationale, 8, 11-36.

Reitz, J.G., Curtis, J., and Elrick, J. (2014), 'Immigrant Skill Utilization: Trends and Policy Issues', Journal of International Migration and Integration, 15, 1-26.

Roberson, L., Galvin, B.M., and Charles, A.C. (2007), 'When Group Identities Matter: Bias in Performance Appraisal', The Academy of Management Annals, 1, 617-650.

Salaff, J., Greve, A., and Ping, L.X.L. (2002), 'Paths into the Economy: Structural Barriers and the Job Hunt for Skilled Migrants in Canada', International Journal of Human Resource Management, 13, 450-464.

Statistics Canada (2014), Labour Force Characteristics by Immigrant Status of Population Aged 25 to 54, and by Educational Attainment, retrieved February 5, 2014, from http://www.statcan.gc.ca/tables-tableaux/sum-som/101/cst01/labor90a-eng.htm 
Tajfel, H., and Turner, J. (1986), ‘The Social Identity Theory of Intergroup Behavior', in Psychology of Intergroup Relations, eds. S. Worchel, and W.G. Austin, Chicago: Nelson-Hall, pp. 7-24.

Thornton, G.C. (1992), Assessment Centers in Human Resource Management, New York: Addison-Wesley.

Zikic, J., Bonache, J., and Cerdin, J.L. (2010), 'Crossing National Boundaries: A Typology of Qualified Immigrants' Career Orientations', Journal of Organizational Behavior, 31, 667-686. 
Table 1. Means and standard deviations of the overall suitability evaluations of qualified and less qualified local and immigrant applicants as a function of fit with clientele

\begin{tabular}{|c|c|c|c|c|c|c|c|}
\hline \multicolumn{2}{|c|}{$\begin{array}{l}\text { Qualified } \\
\text { Locals }\end{array}$} & \multicolumn{2}{|c|}{$\begin{array}{l}\text { Qualified } \\
\text { Immigrants }\end{array}$} & \multicolumn{2}{|c|}{$\begin{array}{c}\text { Less } \\
\text { Qualified } \\
\text { Locals }\end{array}$} & \multicolumn{2}{|c|}{$\begin{array}{c}\text { Less } \\
\text { Qualified } \\
\text { Immigrants }\end{array}$} \\
\hline$M$ & $S D$ & $M$ & $S D$ & $M$ & $S D$ & $M$ & $S D$ \\
\hline
\end{tabular}

Control

condition

$\begin{array}{llllllll}6.03_{\mathrm{e}} & .69 & 5.76_{\mathrm{f}} & .80 & 4.21 & .97 & 4.17 & 1.04\end{array}$

Fit with a

$\begin{array}{lllllllll}\text { homogeneous } & 6.08^{\mathrm{g}} & .68 & 5.56^{\mathrm{h}} & .83 & 4.09 & .85 & 4.04 & 1.04\end{array}$

clientele ${ }^{\mathrm{b}}$

Fit with a diverse

\begin{tabular}{lllllllll} 
clientele $^{\mathrm{c}}$ & $5.88_{\mathrm{i}}$ & .92 & $5.75_{\mathrm{i}}$ & .88 & 4.23 & .90 & 4.34 & 1.05 \\
\hline Column means $^{\mathrm{d}}$ & $5.99^{\mathrm{j}}$ & .77 & $5.69^{\mathrm{k}}$ & .84 & 4.18 & .90 & 4.18 & 1.04
\end{tabular}

Note: ${ }^{\mathrm{a}} n=53 .{ }^{\mathrm{b}} n=57 .{ }^{\mathrm{c}} n=55 .{ }^{\mathrm{d}} n=165$. Overall suitability evaluations were made on a 7 point scale $(1=$ extremely poor to $7=$ extremely good $)$. Among qualified applicants, means in the same row that do not share subscripts differ at $p<.01$. Among qualified applicants, means in the same row that do not share superscripts differ at $p<.001$. Among qualified applicants, means in the same row that share subscripts do not differ. Among less qualified applicants, there were no differences in means in the same row. 
Table 2. Summary of within-between analysis of variance for overall suitability evaluations

\begin{tabular}{|c|c|c|c|c|c|}
\hline Effect & $d f$ & Sum of Squares & Mean Square & $F$ & $\begin{array}{c}\text { Partial } \\
\text { Eta } \\
\text { Squared }\end{array}$ \\
\hline \multicolumn{6}{|l|}{ Between participants } \\
\hline $\operatorname{Sex}^{\mathrm{a}}$ & 1 & 4.24 & 4.24 & 2.08 & .01 \\
\hline $\operatorname{Age}^{\mathrm{b}}$ & 1 & 1.40 & 1.40 & .69 & .00 \\
\hline Ethnicity $^{\mathrm{c}}$ & 1 & 2.32 & 2.32 & 1.14 & .01 \\
\hline Born in Canada ${ }^{\mathrm{d}}(\mathrm{BC})$ & 1 & 8.40 & 8.40 & $4.11^{*}$ & .03 \\
\hline Fit with Clientele & 2 & 2.96 & 1.48 & .73 & .01 \\
\hline Error & 158 & 322.66 & 2.04 & & \\
\hline \multicolumn{6}{|l|}{ Within participant } \\
\hline Immigrant Status (Imm) & 1 & 1.37 & 1.37 & $4.42 *$ & .03 \\
\hline Qualification Level (QL) & 1 & 269.42 & 269.42 & $440.41 * * *$ & .74 \\
\hline Imm X Sex & 1 & .12 & .12 & .38 & .00 \\
\hline Imm X Age & 1 & .34 & .34 & 1.09 & .01 \\
\hline Imm X Ethnicity & 1 & .53 & .53 & 1.69 & .01 \\
\hline Imm X BC & 1 & .24 & .24 & .76 & .01 \\
\hline Imm X Fit with Clientele & 2 & 2.64 & 1.32 & $4.24 *$ & .05 \\
\hline QL X Sex & 1 & .17 & .17 & .28 & .00 \\
\hline QL X Age & 1 & 1.89 & 1.89 & 3.10 & .02 \\
\hline QL X Ethnicity & 1 & .42 & .42 & .68 & .00 \\
\hline QL X BC & 1 & .01 & .01 & .02 & .00 \\
\hline QL X Fit with Clientele & 2 & 1.23 & .61 & 1.00 & .01 \\
\hline QL X Imm & 1 & 1.50 & 1.50 & $6.86^{* *}$ & .04 \\
\hline QL X Imm X Sex & 1 & .01 & .01 & .05 & .00 \\
\hline QL X Imm X Age & 1 & .35 & .35 & 1.59 & .01 \\
\hline QL X Imm X Ethnicity & 1 & .07 & .07 & .33 & .00 \\
\hline QL X Imm X BC & 1 & .04 & .04 & .19 & .00 \\
\hline QL X Imm X Fit with Clientele & 2 & .46 & .23 & 1.05 & .01 \\
\hline Error (Imm) & 158 & 49.16 & .31 & & \\
\hline Error (QL) & 158 & 96.66 & .61 & & \\
\hline Error (QL X Imm) & 158 & 34.45 & .22 & & \\
\hline
\end{tabular}

Note: ${ }^{*} p<.05, * * p<.01, * * * p<.001 . \mathrm{n}=165{ }^{\text {a. }}-.5=$ Male, $+.5=$ Female. ${ }^{\text {b. }}$ Centered, in years. ${ }^{\mathrm{c}} 0=$ White, $1=$ Non-White, ${ }^{\text {d. }} 0=$ Born in Canada, $1=$ Not born in Canada. 
Table 3. Summary of analysis of variance for overall suitability evaluations of qualified applicants

\begin{tabular}{|c|c|c|c|c|c|}
\hline Effect & $D f$ & Sum of Squares & Mean Square & $F$ & $\begin{array}{l}\text { Partial } \\
\text { Eta } \\
\text { Squared }\end{array}$ \\
\hline \multicolumn{6}{|l|}{ Between participants } \\
\hline $\operatorname{Sex}^{\mathrm{a}}$ & 1 & 1.36 & 1.36 & 1.34 & .01 \\
\hline $\operatorname{Age}^{\mathrm{b}}$ & 1 & .02 & .02 & .02 & .00 \\
\hline Ethnicity $^{\mathrm{c}}$ & 1 & .39 & .39 & .38 & .00 \\
\hline Born in Canada (BC) ${ }^{d}$ & 1 & 3.89 & 3.89 & 3.84 & .02 \\
\hline Fit with Clientele & 2 & .48 & .24 & .24 & .00 \\
\hline Error & 158 & 160.47 & 1.02 & & \\
\hline
\end{tabular}

Within participant

Immigrant status (Imm)

Imm X Sex

1.13

1.13

$10.50 * * * \quad .06$

Imm X Age

.03

.03

.10

.00

Imm X Ethnicity

.00

.00

.00

.00

Imm X BC

.49

.49

1.81

.01

Imm X Fit with Clientele 2

.24

.24

.88

.01

Error (Imm)

$158 \quad 43.14$

1.23

$4.51 *$

.05

Note: ${ }^{*} p<.05, * * * p<.001 . \mathrm{n}=165{ }^{\text {a. }}-.5=$ Male, $+.5=$ Female. ${ }^{\mathrm{b}}$ Centered, in years. ${ }^{\mathrm{c} .} 0=$ White, $1=$ Non-White, ${ }^{\mathrm{d}} 0=$ Born in Canada, $1=$ Not born in Canada. 